\title{
Can Synergy Effect Exist between Green Finance and Industrial Structure Upgrade in China?
}

\author{
Ruixiong $\mathbf{Q} \mathbf{i}^{1}$, Long $\mathbf{Q} \mathbf{i}^{2}$ \\ ${ }^{1}$ Business School, Shanxi Datong University, Datong, China \\ ${ }^{2}$ Yungang Cultural Research Center, Shanxi Datong University, Datong, China \\ Email: qrx_dtdx@163.com
}

How to cite this paper: Qi, R. X., \& Qi, L. (2020). Can Synergy Effect Exist between Green Finance and Industrial Structure Upgrade in China? Open Journal of Social Sciences, 8, 215-226.

https://doi.org/10.4236/jss.2020.88019

Received: July 30, 2020

Accepted: August 19, 2020

Published: August 21, 2020

Copyright $\odot 2020$ by author(s) and Scientific Research Publishing Inc. This work is licensed under the Creative Commons Attribution-NonCommercial International License (CC BY-NC 4.0).

http://creativecommons.org/licenses/by-nc/4.0/

\begin{abstract}
The semi-annual data are selected from 2013 to 2018 for empirical research on the relationship between China's green finance and industrial structure as well as the effect of green finance supports industrial structure upgrading. By establishing grey relational and time series dynamic models, conclusions as following: 1) Green finance has a strong grey relational with the three industrial structures; there is a close synergy effect; 2) The second industry has the strongest correlation, followed by the tertiary industry; green finance is of great significance to promote the upgrading; 3 ) Three industrial structures have positive correlation with green finance development and can promot it conversely; the second and the tertiary industry are of high significance level; 4) Green finance can support industrial structure upgrading effectively; green credit and green securities as the leading force have a significantly positive correlation with the upgrading of the industrial structure. Compared, green credit is more obvious and green securities space is still large; 5) Because of cumulative effect and lag effect, previous industrial structure upgrading has a driving effect on the current; lag period is half a year; 6) Increasing R\&D investment and reducing the "two high and one surplus" industries credit scale have a positive effect on upgrading China's industrial structure.
\end{abstract}

\section{Keywords}

Green Finance, Synergy Effect, Grey Relational, Industrial Structure Upgrade

\section{Introduction}

At present, strengthening the construction of ecological civilization, protecting the ecological environment and building a beautiful China have become major national development strategies. China is in an important historical period of 
transformation of development mode and adjustment of economic structure, and the demand for green finance to promote sustainable economic and social development and transformation and upgrading of green industries is increasing. In the next five years, the green industries will need to invest an average of $3 \%$ of GDP annually, amounting to more than two trillion yuan per year. About $10 \%$ to $15 \%$ of the scale of green investment is government investment, while the remaining $85 \%$ to $90 \%$ relies on social capital ${ }^{1}$. Therefore, the development of green and low-carbon economy and the financing demand of green industry are huge and need to be leveraged through innovation in financial tools to develop and improve the green finance system is far-reaching.

Along with the adjustment of industrial structure and the inherent requirements of the green economy, production factors flow from low input-output growth rate or high energy consumption input-output rate to high input-output growth rate or energy-saving input-output rate of sectors and industries to achieve the survival of the fittest in industries. The allocation of resources from high-polluting and energy-consuming industries to environmentally friendly industries promotes sustainable, green and healthy economic development. In recent years, under the policy guidance of actively encouraging the development of green economy and promoting the dynamic adjustment and upgrading of industrial structure in China, the transformation and upgrading of industries can be accomplished with the help of green finance, which is a positive driving force of connotative economic development and has great theoretical and practical significance.

\section{Literature Review}

Foreign scholars have studied green finance earlier and their research results are mainly concentrated in the green finance evaluation system, green finance policy and green finance theory. China's domestic green finance practice started late, mainly focusing on qualitative research on the status quo of China's green finance development and policy recommendations, as well as quantitative research on green finance and green industries, green technological innovation, and green policy effects. The research literature on the relationship between green finance, industrial structure and industrial structure upgrade is limited. The existing results focus on the impact of green credit on the industrial structure and the promotion of industrial structure adjustment.

The impact of China's green credit on the upgrading of industrial structure prove that green credit has a significant effect of adjusting industrial structure through funding channels, and the degree of influence varies greatly in different regions, market-oriented adjustment of credit structure can effectively promote industrial optimization and upgrading (Xu, Zhao, \& Yao, 2018). A variety of green financial instruments can optimize the industrial structure and guide ${ }^{1}$ Quoted from the website of Green Finance Committee of China Finance Association titled on "Research on Green Finance and Green Stock Index", http://www.greenfinance.org.cn/displaynews.php?id=571, 2017.02. 
funds into the environmental protection industry through green bonds, green credit and green insurance (Salazar, 1998). Established an evaluation system for China's green finance development to evaluate China's green finance development level from five dimensions, including green credit, green securities, green insurance, green investment and carbon finance which 11 three-level indicators contained (Zeng, Liu, Man, \& Shen, 2014). The optimization of green finance structure assists enterprises in realizing the R\&D investment required for technological innovation, which is conducive to the development of high-tech industries and promotes industrial structure upgrade (Wang, 2019). Different from traditional financing models, through the innovation of green financial tools, environmental pollution projects are effectively restricted and the development of alternative energy industries is supported, thereby promoting the optimization and upgrading of the industrial structure (Anderson, 2016). Green credit contributes to the development of industries in emerging economies and can promote the rapid development of industries and the formation of new industries (Chu \& $\mathrm{He}, 2016)$. It is found that a non-linear relationship between green credit, technological progress, and industrial structure optimization by using PVAR model. Green credit directly promotes industrial structure optimization than the intermediate variables of technological progress (Zhang \& Zhao, 2019). The empirical research found that the development of green finance can promote the regional industrial structure upgrade, and the effect of developed regions is more significant than that of underdeveloped regions (Dang, 2019). Research on the coordination degree between green finance and industrial structure optimization through the multivariable lagged coordination degree model $\mathrm{GM}(1, \mathrm{~N})$, indicating that the development of green finance is promoting industrial structure optimization (Li \& Jing, 2020).

\section{Theoretical Analysis}

\subsection{Capital Formation Mechanism}

The financial market can absorb the idle capital in the capital market and invest them in target industries to form stable capital for industrial development. The development of green industries requires the injection of capital to realize the investment in technological innovation, and the development of green finance can effectively realize the innovation of financial tools, pooling the funds of the capital market. By issuing green credit, issuing green securities, promoting green insurance and other businesses, it forms a stable financial source for green industry operation, converts capital into investment, effectively reduces the financing cost of enterprises, and rapidly forms the scale of the industry.

\subsection{Fund Oriented Mechanism}

The financial system can optimize the allocation of financial resources through a variety of mechanisms and facilitate the free flow of financial capital across different industries, sectors and regions. In order to compensate for market failure, 
the state or policy-based financial institutions can directly regulate the financial market, while commercial financial institutions optimize financial resources through competition in the capital market in order to achieve the goal of corporate interests. Therefore, under the joint promotion of the government and the market, green finance realizes the money multiplier effect, and funds are multiplied into green industries. The funds of traditional energy-consuming and high-polluting industries are directed to environmentally friendly, energy saving and clean industries, and the financial capital realizes the optimal allocation of industries, thus forming the upgrade of industrial structure.

\subsection{Industrial Integration Mechanism}

Under the guidance of the national low-carbon and clean policy, enterprises will redistribute production factors across industries, regions and ownership structures, and integrate them according to the rules of industrial development to form corresponding industrial structures so as to seek long-term development and competitive advantages. As the main source of capital supply, the modern financial market can provide industrial integration, especially the demand for capital for the development of green industries, green industry integration will break through the barriers of countries, regions and industries, and realize the reallocation of resources in the labor market, commodity market, financial market and technology market in a broader scope, improve the market system to further exert the scale economy effect of green industry, and green capital to maximize the synergy with the industry.

\subsection{Information Transmission Mechanism}

There is an asymmetry of information in the financial market, which makes it impossible to obtain complete information about the future investment projects of the invested companies and does not guarantee the investment of funds in safe projects. In order to regulate and ensure the rational allocation of resources, green finance means can be fully utilized in the financial system, such as new green projects can be encouraged by the issuance of green loans, financial subsidies, equity financing and other means of encouragement to the public and the market to convey the signal of national support for the development of green clean, environmentally friendly and energy-efficient industries, to reduce the risk assessment of investors on emerging green industry projects, to reduce the instability of private capital, and to strive for more participants and suppliers for green industry investment and industrial upgrade.

\subsection{Risk Allocation Mechanism}

Compared with traditional industries in the past, the emerging green industry is not yet mature, and the broad development prospect is also accompanied by high investment risks. There is also a problem of risk redistribution in the financial market when the financial market reallocates funds and investors are faced 
with a major consideration of risk choices when investing. The traditional industry is large in scale and relatively low in investment risk; conservative investors in the capital market still choose to invest in industries with high energy consumption and high pollution due to risk aversion. However, green finance plays a role of risk redistribution in the financial market, risk-averse investors will withdraw from traditional industries and turn to emerging green industries for risk balancing and prospect considerations, effectively driving the adjustment and upgrading of industrial structure.

\section{Empirical Analysis}

\subsection{Data and Variable Selection}

The green finance system is a series of institutional arrangements that guide the green development of economy through relevant policies and multiple financial instruments, and rationally allocate funds flow direction through green bonds, green credit, green development funds, green stock indexes and related products, carbon finance, green insurance, etc. Since China's corporate environmental liability insurance was only compulsorily introduced at the end of 2013, statistical data is not complete and cannot be included in research scope. The carbon emission trading market has been piloted since 2013 and has been launched in 9 provinces by the end of 2016, with the level of development and inactive trading, so this article is not included in research scope. China's green finance started late, green credit as the main content. China's banking social responsibility report began to disclose the balance of green credit from 2011, but only the loan balance of energy-saving and environmental protection projects was disclosed before 2013, with different caliber. Therefore, the year semi data in this paper selects the proportion of green credit balance to RMB loan balance in 2013-2018, and collects and sorts from the social responsibility report disclosed by China Banking Association. Green development fund, green stock indexes and related products are included in green bond index. Due to the lack of systematic statistics, this article uses alternative indicators and draws on the ratio of market value of environmental protection industries and six intensive energy consuming industries to represent the ratio of green securities (Zeng, Liu, Man, \& Shen, 2014), the data compiled from the CSMAR database ${ }^{2}$. China's green finance started late, in terms of the current development situation, it is mainly based on green credit. One of the green finance variables in this paper will select the proportion of green credit in the total loans of the year, the index reflects the credit support of financial institutions for low-carbon environmental protection enterprises, and basically reflects the scale and development of green finance in China. According to industrial structure evolution theory, the adjustment of industrial structure measured by the proportion of output value of three major ${ }^{2}$ CSMAR database (China Stock Market \& Accounting Research Database) is a research-oriented and accurate database in the field of economic and financial academic research, drawing on CRSP, COMPUSTAT, TAQ, THOMSON and other authoritative database professional standards, combined with the actual situation of China. 
industries in GDP, and the upgrading of industrial structure measured by the proportion of output value of secondary and tertiary industries in GDP, the designation and definition of variables showing in Table 1.

\subsection{Grey Relational Analysis between Green Finance and Industrial Structure}

1) Model 1

Select the fixed sequence as the reference sequence in original time series data, denoted as $X_{0}$, then select the comparison sequence with the same dimension of $n$ and mark as $X_{i}(i=1,2,3, \cdots)$, so the grey relational coefficient is:

$$
\xi_{i}(k)=\frac{\min _{i} \min _{k}\left|X_{0}^{(1)}(k)-X_{i}^{(1)}(k)\right|+\rho \times \max _{i} \max _{k}\left|X_{0}^{(1)}(k)-X_{i}^{(1)}(k)\right|}{\left|X_{0}^{(1)}(k)-X_{i}^{(1)}(k)\right|+\rho \times \max _{i} \max _{k}\left|X_{0}^{(1)}(k)-X_{i}^{(1)}(k)\right|}
$$

The range of distinguishing coefficient $\rho$ is between $[0,1]$. In general, $\rho=0.5$. $\max _{i} \max _{k}\left|X_{0}^{(1)}(k)-X_{i}^{(1)}(k)\right|$ is the second-level maximum difference expression;

$\min _{i} \min _{k}\left|X_{0}^{(1)}(k)-X_{i}^{(1)}(k)\right|$ is the second-level minimum difference expression.

The grey relational is expressed as: $r_{i}=\frac{1}{n} \sum_{k=1}^{n} \xi_{i}(k)$.

The model scientifically uses the principle of correlation to measure the relationship between variables, takes the geometric similarity of the sequence as the judging basis of relational, and conducts a quantitative analysis of the interactive relationship situation in system, especially for dynamic process research.

Table 1. Designation and definition of variables.

\begin{tabular}{|c|c|c|c|}
\hline Designation & Symbol & & Definition \\
\hline \multicolumn{4}{|l|}{ Explained variable } \\
\hline $\begin{array}{l}\text { Industrial structure } \\
\text { upgrade }\end{array}$ & & UIS & $\begin{array}{l}\text { (Added value of secondary industry }+ \\
\text { Added value of tertiary industry)/GDP }\end{array}$ \\
\hline \multicolumn{4}{|l|}{ Explanatory variables ${ }^{1}$} \\
\hline Green finance & Green & GR & Green credit balance/RMB loan balance \\
\hline Green securities & $\begin{array}{l}\text { finance, } \\
\text { GF }\end{array}$ & GS & $\begin{array}{l}\text { Related enterprises market value/the } \\
\text { market capitalization of A shares }\end{array}$ \\
\hline \multicolumn{4}{|l|}{ Explanatory variables ${ }^{2}$} \\
\hline Proportion of primary industry & Industrial & $\mathrm{IS}_{1}$ & Added value of primary industry/GDP \\
\hline Proportion of secondary industry & structure, & $\mathrm{IS}_{2}$ & Added value of secondary industry/GDP \\
\hline Proportion of tertiary industry & IS & $\mathrm{IS}_{3}$ & Added value of tertiary industry/GDP \\
\hline \multicolumn{4}{|l|}{ Control variable $^{1}$} \\
\hline Technical progress & & $\mathrm{T}$ & R\&D expenditure/GDP \\
\hline Green industry & & G & $\begin{array}{l}\text { 1-“Two high and one surplus" industry } \\
\text { loan balance/RMB loan balance }\end{array}$ \\
\hline
\end{tabular}


Refer to the weight ratio of green credit and green securities 1.8:1 in the measurement and analysis of green finance development degree in China (Zeng, Liu, Man, \& Shen, 2014). In this article, green credit and green securities are constructed according to the weight ratio of $65 \%$ and $35 \%$ respectively to construct the green finance indicator GF. Through grey relational model, the grey relational between GF and the Primary, secondary, tertiary industries IS $_{1}, \mathrm{IS}_{2}$ and $\mathrm{IS}_{3}$ ), are respectively: $\xi_{i s 1}=0.51, \xi_{i s 2}=0.83, \xi_{i s 3}=0.72$. The empirical results demonstrate: $\xi_{i s 2}>\xi_{i s 3}>\xi_{i s 1}$, reflect the strongest grey relational between green finance and the proportion of the secondary industry added value in GDP, followed by the tertiary industry and the primary industry.

2) Grey relational analysis

The empirical results demonstrate that the data series between green finance and secondary industry output value exist a relatively high degree of geometric similarity, followed by the tertiary industry and the primary industry, and there is a significant correlation overall. In comparison, the secondary industry and green finance have a higher degree of synergy, if green finance is developed more comprehensively, the secondary industry will benefit more widely, which will help the secondary industry upgrade to the tertiary industry, and the tertiary industry also benefit, the three major industries will realize orderly adjustment.

\subsection{Interaction between Green Finance and Industrial Structure Upgrade}

\section{1) Model 2}

Industrial structure upgrading has cumulative effects and lag effects, the adjustment of industrial structure in previous periods is related to the transformation and upgrading of current period. Therefore, the upgrading of the industrial structure in previous period is taken as an explanatory variable to establish the time series dynamic model and introduce the lagging 1 period explanatory variable $U I S_{t-1}$ for regression analysis, the research model:

$$
U I S_{t}=\alpha_{1} U I S_{t-1}+\alpha_{2} G R_{t}+\alpha_{3} G S_{t}+\alpha_{4} T_{t}+\alpha_{5} G_{t}+\varepsilon_{t}
$$

Among them, $t=1,2,3, \cdots$, represents the half-year period of different years, $\varepsilon_{t}$ is the random error term, $U I S_{t-1}$ and $U I S_{t}$ represent $t-1$ and $t$ period's industrial structure upgrade ratio, $G R_{t}, G S_{t}$ represent the green credit and green securities ratio of $t$ period, $T_{t}$ represents the R\&D investment rate of period $t$, and $G_{t}$ represents the industrial greening rate of period $t$.

China's three major industries all cover green enterprises. The quality and scale of green enterprises upgraded under the guidance of green finance policies, forming the adjustment of three major industrial structures, especially the secondary industry is moving towards the tertiary industry which provides the possibility of green finance in the aspects of ecology, environmental protection and energy conservation. Therefore, green finance is inseparable from the adjustment and upgrading of industrial structure, and the changes in proportion of the three major industries in GDP also provides space for green finance, establish 
the research model:

$$
G F_{t}=\beta_{1} I S_{1 t}+\beta_{2} I S_{2 t}+\beta_{3} I S_{3 t}+\mu_{t}
$$

Among them, $t=1,2,3, \cdots$, represents the half-year period of different years, $\mu_{t}$ is the random error term, $G F_{t}$ represents the green finance rate of period $t$, $I S_{10} I S_{2 b} I S_{3 t}$ respectively represent the primary, secondary and tertiary industries accounted for the proportion of GDP.

2) Time series dynamic model analysis

The introduction of 1 period lagging variable $U I S_{t-1}$, conduct an econometric analysis of LR, AIC, FPE, SC, and HQ criteria to test whether the lagging 1 period is reasonable. At the $5 \%$ significance level, the lag coefficients respectively: $61.22793^{*},-7.257287^{*}, 1.10 \mathrm{e}-08^{*},-6.533841^{*}$ and $-7.713318^{*}$, which all passed the test and have sufficient degrees of freedom, so the model (1) is reasonable.

In model (1), showing in Table 2, parameter estimation results demonstrate: industrial structure upgrade in the previous period is positively correlated with the current, which is significant at the $1 \%$ level. When the industrial structure upgrade in the previous period increases by $1 \%$, the current industrial structure upgrade will increase by $0.8829 \%$. Based on this dynamic adjustment process, the industrial structure upgrade is inseparable from previous and the adjustment period is half a year, the industrial structure upgrade period is relatively fast.

The regression coefficients of green credit GR and green securities GS are both positive, respectively 2.999837 and 0.400492 , which proves that green finance makes large contribution rate to the upgrading of China's industrial structure and is positively correlated. As the main component of green finance, green credit ratio will increase by $2.9998 \%$ in current period when green credit ratio increases by $1 \%$, which is significant at the level of $1 \%$. Green securities will bring an increase of $0.4005 \%$ at the significant level of $5 \%$. Therefore, the driving force of China's green finance is still green credit, and there is still a large space for the development of green securities. The regression coefficient of technological progress and industrial greening is positive, indicating that the two are positively correlated with industrial structure upgrade. When the proportion of R\&D expenditure in GDP increases by $1 \%$, the current industrial structure upgrade increases by 7.5014 , which proves that $\mathrm{R} \& \mathrm{D}$ activities bring about tremendous changes in industrial structure at the $1 \%$ significance level, which can quickly realize the industrial structure upgrade from the secondary industry to the tertiary industry. The proportion of green industry increased by $1 \%$, the current industrial structure upgrade increased by $1.26 \%$, which proved effective in reducing the "two high and one surplus" industry (resource-based industries with high pollution and high energy consumption, overcapacity industry) loan rate can promote the industrial structure upgrade, and the guiding effect of credit policy is significant.

3) Analysis of industrial structure promote green finance

In model (2), showing in Table 2, parameter estimation results demonstrate: the proportion of China's three major industries $\left(\mathrm{IS}_{1}, \mathrm{IS}_{2}\right.$, and $\left.\mathrm{IS}_{3}\right)$ is positively 
Table 2. The relationship between green finance and industrial structure: regression results.

\begin{tabular}{|c|c|c|c|}
\hline $\mathrm{UIS}^{1} / \mathrm{GF}^{2}$ & Variable & Regression coefficients & T-statistic \\
\hline \multirow[t]{3}{*}{ Explanatory variables ${ }^{1}$} & UIS (lag1) & 0.882923 & $4.165894^{* * *}$ \\
\hline & GR & 2.999837 & $3.575545^{* * *}$ \\
\hline & GS & 0.400492 & $3.197700^{* *}$ \\
\hline \multirow[t]{2}{*}{ Control variable ${ }^{1}$} & $\mathrm{~T}$ & 7.501365 & $4.574244^{* * *}$ \\
\hline & G & 1.260047 & $3.912040^{* * *}$ \\
\hline \multirow[t]{3}{*}{ Explanatory variables ${ }^{2}$} & IS1 & 0.080343 & 1.419376 \\
\hline & IS2 & 0.113379 & $4.681308^{* * *}$ \\
\hline & IS3 & 0.057646 & $3.963364^{* * *}$ \\
\hline
\end{tabular}

**, "* and " represent the significance of the $P$ value at $1 \%, 5 \%$ and $10 \%$ respectively.

correlated with green finance development, which can play a reverse role in promoting. The regression coefficients of $\mathrm{IS}_{1}, \mathrm{IS}_{2}$, and $\mathrm{IS}_{3}$ on GF respectively are $0.0803,0.1134,0.0576$. Compared with the secondary industry, the reverse driving effect is higher. At the significance level, $P$ value of the secondary industry and the tertiary industry are both significant at the $1 \%$ level, while the primary industry is not. The results are completely consistent with that obtained by the grey relational model, which further proves that the rise in primary industry ratio is not closely related to green finance development. The adjustment of industries, especially the secondary industry which provides growth soil for green finance, the relationship between the two is so close and mutually promotes.

\section{Conclusion and Suggestions}

This article selects the semi-annual data of China's green finance development, the industrial structure proportion and industrial structure upgrade from 2013 to 2018 for empirical analysis, and draws the following conclusions through the establishment of grey relational analysis and time series dynamic analysis models:

Firstly, there is a close interaction between green finance development and three industrial structures in China. The development of green finance has a strong grey relational with the three industrial structures and there is a close synergistic effect. Among them, the secondary industry has the strongest correlation degree, then the tertiary industry, and finally the primary industry. At the same time, the three industrial structures are positively correlated with the green finance development. The industrial structure can act in reverse on the development of green finance and play a positive role in promoting it. The secondary and tertiary industries have high levels of significance, while the primary industry has a low level of significance.

Secondly, the green finance development in China can effectively drive the industrial structure upgrade. Green credit and green securities, as the leading 
forces for the development of green finance at the present stage, are significantly positively correlated with the industrial structure upgrade. Compared with the two, the driving effect of green credit is more obvious, and there is still a large space for the development of green securities. In addition, the upgrading of the industrial structure has cumulative and lagging effects, and the upgrading of the industrial structure in the early period will have a significant driving effect on the current industrial structure, with a lag period of a half year. Besides, increasing $\mathrm{R} \& \mathrm{D}$ investment and reducing the "two high and one surplus" industry credit scale have a positive effect on China's industrial structure upgrade.

Based on the above research conclusions, this article makes the listed suggestions:

1) Accelerate the improvement of green finance system

First of all, deepen the construction of green finance organization system, increase the participants of green finance market, cultivate green finance intermediary institutions and build a green finance workforce. Secondly, promote innovation in green finance instruments, optimize and upgrading green credit, explore green capital markets, popularizing green insurance, improve green investment efficiency and vigorously develop carbon finance. In addition, the design of the green finance system and environment should be improved, and a unified green assessment framework and standard system should be formulated.

2) Connect green finance and industrial policies effectively

Support and encourage secondary and tertiary industries to actively introduce green capital to accelerate industrial integration and upgrading. In the process of financing, financial institutions formulate standard criteria for green credit and green securities, conduct research and evaluation on target enterprises, evaluate the sustainability and ecological protection of projects, predict the environmental costs of projects, and strictly follow the standard assessment and approval, so that enterprises can truly achieve sustainable development and actively assume social responsibility, and make green finance run through the upgrading of industrial structure and the whole process of green economic development.

3) Establish a sound environmental information disclosure system

Mandatory disclosure of enterprise environmental information on a regular basis makes public reports on the status of environmental pollution treatment, to make environmental treatment information open and transparent, to prevent, identify and supervise the risks of green finance, to build a real-time information exchange platform between enterprises, financial institutions and the government, to be reviewed and supervised by the relevant departments, to create a good environment for the flow of green funds and to reduce the risks of green finance.

4) Optimize green finance compensation mechanism and encourage green investment behavior

To encourage financial institutions to increase investment in green credit resources by means of policy formulation, government procurement, price subsidies, discount interest loans and support innovative capital operation in the se- 
curities market. Gradually withdraw from the credit scale of "two high and one surplus" industries, and continue to strengthen the industrial integration and upgrading of green industries. At the same time, green project investment information should be made public and shared, exchanges and cooperation among green enterprises should be strengthened, and the construction of investment and financing information platforms should be promoted to create a favorable investment environment for the suppliers of funds.

Specifically, for energy consumption and pollution emissions that can be easily quantified and monitored, policies such as prices, taxes and financial subsidies can be used to guide changes in resource consumption and production patterns and improve efficiency, such as adjusting traditional energy consumption through tiered prices, increasing the profitability of green production or increasing the cost of pollution, promoting capital investment in green development projects through subsidized loans or risk compensation, and combining green credit with energy saving and emission reduction, circular economy. In addition, consideration can be given to adding provisions in the government procurement law to give priority to the procurement of green products and services, clarify procurement rules and ratios, and open up markets for them, while local governments can also cooperate with social capital to attract social capital to participate in public environmental protection projects.

\section{The Innovation and Limitation}

The current research on green finance is mainly qualitative research, and relatively few quantitative measures. In terms of construction of green finance system, due to limited data access, most scholars only replace green finance with green credit indicator. This paper uses green credit and green bonds to build research model to make up for this deficiency. At the same time, scholars have seldom studied the synergy between green finance and industrial structure upgrade, this article innovatively uses grey relational and time series dynamic analysis models to empirically study the mechanism and interaction of green finance in promoting industrial structure adjustment, which provides important theoretical support for the transformation of traditional finance to green finance and the upgrading and development of industrial structure. In addition, the use of semi-annual data greatly expands the research sample, makes the research conclusions more detailed and more reliable.

The complete green financial system includes green credit, green bonds, green funds, green insurance, green stock indexes and related products, carbon finance, etc. Due to the absence of statistical data and non-mandatory disclosure, the only indicators of green credit and green bonds used in this paper based on which account for a large proportion of green finance, but have certain limitations in the study of green finance system. Besides, there is also plenty room for improvement in the use of alternative indicators of green bonds. Therefore, in the subsequent research process, the green financial system will be further enriched, 
and direct indicators will be used as much as possible with the standardization and improvement of disclosure. At the same time, further incorporate the latest data, expand the time range of the research samples, and make the research conclusions more convincing and guiding.

\section{Fund}

This article is phased research result: Datong City's National Green Finance Reform and Innovation Pilot Zone Project "How to establish a green finance system to promote the high-quality economic development of Datong City" (No. SXSJ-F3180621) supported by Datong Development and Reform Commission; Youth Research Fund Project "Research on Strategic Choice Path of Tongmei Group under the Resource-based Economy Transformation Background in Datong” (No. 2018Q19) supported by Shanxi Datong University.

\section{Conflicts of Interest}

The authors declare no conflicts of interest regarding the publication of this paper.

\section{References}

Anderson, J. (2016). Environmental Finance. In G. N. Gregoriou, \& V. Ramiah (Eds.), Handbook of Environmental and Sustainable Finance (pp. 307-333). Amsterdam: Elsevier Inc. https://doi.org/10.1016/B978-0-12-803615-0.00015-7

Chu, E. M., \& He, X. (2016). The Interaction Mechanism and Empirical Research of Financial Structure and Industrial Structure. Statistics and Decision, 7, 168-171.

Dang, C. L. (2019). The Relationship between Regional Green Finance Development and Industrial Structure: An Empirical Analysis Based on China's Provincial Panel. Business Economics Research, 15, 143-145.

Li, Q., \& Jing, L. (2020). Analysis of Green Finance and Industrial Structure Optimization-Multivariable GM $(1, \mathrm{~N})$ Coordination Model Based on Time Delay. Journal of Lanzhou University of Arts and Science (Social Sciences), 36, 86-92.

Salazar, J. (1998). Environmental Finance: Linking Two World. In A Workshop on Finance Innovations for Biodiversity Bratislava (pp. 2-18).

Wang, R. (2019). Green Finance, Technological Innovation and Green Policy-An Empirical Analysis Based on Coupling Model and Grey Relational Model. Investigation in Financial Theory, 6, 60-70.

Xu, S., Zhao, X. X., \& Yao, S. (2018). Analysis of the Effect of Green Credit on the Up-Grading of Industrial Structure. Journal of Shanghai University of Finance and Eco-nomics, 20, 59-72.

Zeng, X. W., Liu, Y. Q., Man, M. J., \& Shen, Q. L. (2014). Measurement and Analysis of the Development Level of Green Finance in China. Journal of China Yan'an Executive Academy, 7, 112-121+105.

Zhang, Y. H., \& Zhao, J. H. (2019). Green Credit, Technological Progress and Industrial Structure Optimization-An Empirical Analysis Based on the PVAR model. Finance and Economy, 4, 43-48. 